\title{
Reflection/impulsivity and field dependence/ independence in retarded and nonretarded children of equal mental age
}

\author{
RICHARD M. GARGIULO \\ Department of Special Education, Bowling Green State University, Bowling Green, Ohio 43403
}

\begin{abstract}
Sixty educable mentally retarded and 60 nonretarded children of equal mental age were assessed using Kagan's Matching Familiar Figures Test (MFFT) and the Children's Embedded Figures Test (CEFT). Significant differences were not observed in the error and latency scores of the two groups or in the proportion of reflective, impulsive, fast/accurate, and slow/inaccurate individuals. The mentally retarded students were significantly more field dependent, as were subjects characterized as impulsive. A significant negative correlation was obtained between MFFT errors and the number of correct responses on the CEFT. IQ was unrelated to performance on either dependent measure. The results were discussed in terms of theoretical and educational implications.
\end{abstract}

Special education has historically been concerned with the exploration and identification of individual differences. One area that has received considerable attention is cognitive style, that is, the characteristic way in which an individual conceptually organizes the environment. Two dimensions of cognitive style that have been extensively investigated are reflection/impulsivity (R/I) (Kagan, Rosman, Day, Albert, \& Philips, 1964) and Witkin's construct of field dependence/independence (FD/I) (Witkin, Dyk, Faterson, Goodenough, \& Karp, 1962).

Kagan proposed that $\mathrm{R} / \mathrm{I}$ refers to the degree to which an individual reflects on the validity of his solution hypotheses to problems with response uncertainty (Kagan \& Kogan, 1970). This dimension has operationally been defined by the Matching Familiar Figures Test ${ }^{1}$ (MFFT; Kagan et al., 1964), which measures latency to the first response and the total number of errors. The reflective individual is below the median in errors but above the median in response time, whereas the impulsive individual is defined as being above the median in errors but below the median in reaction time.

Witkin and his collaborators defined FD/I as the ability to separate an item from the field in which it is embedded (Witkin et al., 1962). Individuals who are able to overcome the influence of an organized perceptual field by distinguishing parts from the whole are considered field independent; those subjects influenced more by the background, who have difficulty in separating an item from its context, are called field dependent. This dichot-

This research was supported by a Faculty Research Grant awarded by Bowling Green State University. Requests for reprints should be directed to Richard M. Gargiulo, Department of Special Education, Bowling Green State University, Bowling Green, Ohio 43403. omy is further conceptualized in terms of differences in the degree to which perception is global and diffuse (field dependent) or structured and analytic (field independent). Field dependency is assessed by measures that require the subject to isolate figures embedded in complex backgrounds.

The dimensions of $\mathrm{R} / \mathrm{I}$ and $\mathrm{FD} / \mathrm{I}$ have generated a plethora of research involving both handicapped and nonhandicapped learners (Keogh, 1973; Messer, 1976). However, there is debate over the relationship of R/I and FD/I. Kagan's early research indicated "no strong relation between field independence and reflectionimpulsivity" (Kagan et al., 1964, p. 35), but Davis (Note 1) has suggested that these two dimensions are related, since aspects of both involve styles of analysis of a stimulus complex. In support of Kagan, Keogh's (1973) review speculated that $\mathrm{R} / \mathrm{I}$ and $\mathrm{FD} / \mathrm{I}$ were relatively independent functions affecting performance on problem solving tasks. Campbell and Douglas (1972), however, hypothesized that the constructs of $R / I$ and FD/I have common cognitive components and should covary. Other researchers reported that reflective children were more field independent than their impulsive counterparts (Massari, 1975; Schleifer \& Douglas, 1973), even after differences in intelligence were controlled (Campbell, 1973). Thus, the issue of a relationship between $\mathrm{R} / \mathrm{I}$ and $\mathrm{FD} / \mathrm{I}$ remains obscure.

The intent of the present study was to investigate this relationship in mildly retarded and nonretarded children. The literature is especially sparse when addressing this topic; with two exceptions, none of the available reports included a comparison of retarded and nonretarded individuals. Furthermore, neither investigation examined the dimensions of R/I and FD/I simultaneously. The existing research suggests that mildly retarded adolescents and nonretarded children of equal mental 
age (MA) do not significantly differ in their performance on the MFFT (Borys \& Spitz, 1978). However, when considering the performance of MA-matched retarded and nonretarded children on measures of field dependence, Nesbit and Chambers (1976) reported that the performance of the retarded subjects was significantly lower than that of their nonretarded counterparts. The nonretarded youngsters exhibited a field-independent cognitive style, in contrast to the field dependency of the retarded adolescents.

It was hypothesized, therefore, that mildly retarded and nonretarded children would perform similarly on the MFFT, although retarded individuals would exhibit a field-dependent cognitive style. It was also expected that impulsive youngsters would be significantly more field dependent. Finally, a significant relationship was anticipated among MFFT errors, latency, and field dependency.

\section{METHOD}

\section{Subjects}

The subjects consisted of 60 mildly (educable) retarded children ( 35 boys, 25 girls) and 60 nonretarded children (35 boys, 25 girls). The educable retarded (EMR) subjects were chosen from self-contained special education classrooms within a rural county school system. The nonretarded youngsters were selected from elementary classrooms located in the same district. The children were predominantly white and lower class. All subjects were free from observable physical or sensory handicaps. Mean chronological age (CA) and MA for the nonretarded children were $6.69(\mathrm{SD}=.35)$ and $7.30(\mathrm{SD}=.96)$ years, respectively. The retarded subjects had a mean CA of 9.77 years $(\mathrm{SD}=1.77)$ and a mean MA of 7.30 years $(S D=1.36)$. The mean IQ for each group was 105.21 (SD = 8.34) and 64.37 (SD = 4.90) respectively.

\section{Instruments}

Matching Familiar Figures Test (MFFT). R/I was assessed by the MFFT (Kagan et al., 1964). This visual discrimination assessment consisted of 14 sets of familiar pictures (e.g., teddy bear, telephone), 2 practice and 12 test items. The individual was shown a standard stimulus and six similar variants and was required to select the picture identical to the standard. The standard and possible choices were presented simultaneously. If the subject made an incorrect choice, he was required to choose again until the correct stimulus was chosen. Latency to the first response and the total number of errors were recorded.

Children's Embedded Figures Test (CEFT). Developed by Karp and Konstadt (1971), the CEFT was used as the measure of FD/I. The CEFT consisted of 25 chromatic test items and 2 practice items in which a smaller figure was embedded within a larger one. The first series consisted of 11 items in which a triangle ("tent") was embedded, and the remaining 14 items in the second series had a house-shaped figure ("house") embedded. The score was the total number of figures correctly located, with latency not recorded. Feedback regarding accuracy of choice was not provided, and only one trial was allowed per item. Testing was discontinued after five consecutive failures.

\section{Procedure}

After obtaining parental consent, a female experimenter individually assessed the subjects in a small examination room located in each building. Approximately 2 weeks prior to administering either the MFFT or the CEFT, the EMR subjects received the Peabody Picture Vocabulary Test (PPVT; Dunn, 1965). Upon determining the mean MA of the retarded subjects, nonretarded children were also assessed with the PPVT and matched on MA with the retarded children. The proportion of boys and girls in each group was maintained. After establishing equivalence of MA, the subjects received either the MFFT or the CEFT in accordance with instructions provided in the administrator's manual. To control for order of testing, 30 retarded and 30 nonretarded subjects were randomly selected to receive the MFFT and the remaining individuals were administered the CEFT. Upon completion of this assessment phase, those children evaluated with the MFFT were administered the CEFT and students assessed with the CEFT received the MFFT.

After completion of the entire test administration, a double median split was conducted for all 120 subjects. Median latency to the first response was $8.0 \mathrm{sec}$, and 17 was the median number of total errors. This procedure identified 40 nonretarded and 42 EMR children as being either impulsive or reflective.

\section{RESULTS}

A 2 by 2 (sex by group) multivariate analysis of variance procedure (Barr, Goodnight, Sall, \& Helwig, 1979) indicated no significant differences in errors and latency between boys and girls and retarded and nonretarded students on the MFFT $[\mathrm{F}(2,112)=2.20$, $\mathrm{p}=.11$, and $\mathrm{F}(2,112)=.24, \mathrm{p}=.78$, respectively] Similarly, the covariate of MA was also nonsignificant $[F(2,112)=1.85, \mathrm{p}=.15]$.

The results of a 2 by 2 chi-square analysis further indicated that the EMR pupils did not significantly differ in cognitive style from their nonhandicapped peers $\left(\chi^{2}=.205, p>.10\right)$. To test whether there were any differences between the two groups in the relative frequency of fast/accurate and slow/inaccurate subjects, a Fisher exact test (Everitt, 1977) was conducted, which yielded a nonsignificant probability of .41 . Similar results were observed when comparing males and females.

The anticipated negative correlation between errors and latency on the MFFT was evidenced by both groups of students. Table 1 presents the mean errors and mean latency to the first response for each group, in addition to the correlation coefficients.

A 2 by 2 (group by sex) analysis of variance confirmed that the mentally retarded subjects were significantly more field dependent $[F(1,116)=22.78$, $\mathrm{p}<.0001$ ] . Significant differences were not observed, however, between boys and girls $[F(1,116)=.56$, $\mathrm{p}=.45]$. The mean number correct for the retarded subjects on the CEFT was $8.06(\mathrm{SD}=4.25)$ vs. 12.23

Table 1

Mean Error and Latency Scores for Retarded and Nonretarded Students and Male and Female Subjects

\begin{tabular}{lrrrrrrr}
\hline & & \multicolumn{2}{c}{ Errors } & & \multicolumn{2}{c}{ Latency } & \\
\cline { 3 - 4 } \multicolumn{1}{c}{ Group } & $\mathrm{N}$ & Mean & SD & & Mean & SD & r \\
\hline Educable Retarded & 60 & 18.05 & 6.87 & & 8.75 & 4.08 & -.557 \\
Nonretarded & 60 & 17.81 & 5.66 & & 8.39 & 4.36 & -.554 \\
Male & 70 & 18.92 & 6.51 & & 8.10 & 3.40 & -.543 \\
Female & 50 & 16.54 & 5.69 & & 9.23 & 5.09 & -.575 \\
Total & 120 & 17.93 & 6.27 & & 8.57 & 4.21 & -.550 \\
\hline
\end{tabular}

Note $-p=.0001$ in all cases. 
$(\mathrm{SD}=4.82)$ for nonretarded individuals. Likewise, the mean number correct for males $(\mathrm{N}=70)$ was 9.88 $(\mathrm{SD}=4.76)$ vs. $10.52(\mathrm{SD}=5.31)$ for females $(\mathrm{N}=50)$. A significant interaction was not evidenced $(p=.96)$.

Further analysis of the data suggested a relationship between error scores on the MFFT and the number of correct responses on the CEFT $[F(1,117)=10.94$, $\mathrm{p}<.001]$. Specifically, the more errors committed on the MFFT, the fewer responses were correct on the CEFT $(\mathrm{r}=-.39, \mathrm{p}<.0001)$. Reaction time on the MFFT did not contribute to performance on the CEFT $(F=.85, p=.35)$. However, after adjusting for the effect of errors on the MFFT, significant differences were still evident between the retarded and nonretarded children $[F(1,115)=26.71, p<.0001]$.

The performance of reflective and impulsive individuals on the CEFT was also assessed via a 2 by 2 (cognitive style by group) analysis of variance. The impulsive subjects $(\mathrm{N}=43)$ were significantly more field dependent than the reflectives $(\mathrm{N}=39)[\mathrm{F}(1,78)=16.04$, $\mathrm{p}<.0001]$. The mean number correct for the impulsive youngsters was $8.04(\mathrm{SD}=4.36)$ vs. $11.48(\mathrm{SD}=4.34)$ for their reflective peers. When examining the performance of reflective and impulsive retarded and nonretarded children, we found that the results were similar to those previously reported. The EMR $(\mathrm{N}=42)$ were significantly $[F(1,78)=13.72, p<.0004]$ more field dependent than their nonretarded $(\mathrm{N}=40)$ counterparts (8.14, $\mathrm{SD}=4.40$, vs. $11.30, \mathrm{SD}=4.40$, respectively). The interaction of Cognitive Style by Group was nonsignificant $(p=.98)$. Table 2 presents the mean number correct on the CEFT for retarded and nonretarded reflective and impulsive individuals.

In order to determine whether individual children were field independent or field dependent, a median split was conducted on the CEFT scores. Subjects below the median of 10 were dichotomized as field dependent, and those above the median were considered field independent. Individuals with a score of 10 were deleted from further consideration.

A 2 by 2 (field independent/field dependent by group) multivariate analysis of variance indicated significant differences between field-independent and fielddependent individuals on the MFFT $[\mathrm{F}(2,108)=7.22$, $\mathrm{p}<.001]$. As expected, significance was not observed between retarded and nonretarded subjects $[\mathrm{F}(2,108)=$ $2.57, p=.08]$. Follow-up univariate analyses demonstrated that field-independent $(\mathrm{N}=56)$ and fielddependent $(\mathrm{N}=57)$ children differed in both errors and

Table 2

CEFT Performance for Retarded and Nonretarded Impulsive and Reflective Subjects

\begin{tabular}{lcccccccc}
\hline & \multicolumn{3}{c}{ Impulsive } & & \multicolumn{3}{c}{ Reflective } \\
\cline { 2 - 4 } \cline { 7 - 8 } \multicolumn{1}{c}{ Group } & N & Mean & SD & & N & Mean & SD \\
\hline Educable Retarded & 21 & 6.33 & 3.87 & & 21 & 9.95 & 4.23 \\
Nonretarded & 22 & 9.68 & 4.24 & & 18 & 13.27 & 3.84 \\
\hline
\end{tabular}

Table 3

MFFT Error and Latency Scores for Retarded and Nonretarded Field-Independent (FI) and Field-Dependent (FD) Subjects

\begin{tabular}{|c|c|c|c|c|c|c|c|}
\hline \multirow[b]{2}{*}{ Group } & & \multirow[b]{2}{*}{$\mathrm{N}$} & \multicolumn{2}{|c|}{ Errors } & \multicolumn{2}{|c|}{ Latency } & \multirow[b]{2}{*}{$\mathrm{r}$} \\
\hline & & & Mean & SD & Mean & SD & \\
\hline $\begin{array}{l}\text { Educable } \\
\text { Retarded }\end{array}$ & $\begin{array}{l}\text { FI } \\
\text { FD }\end{array}$ & $\begin{array}{l}15 \\
41\end{array}$ & $\begin{array}{l}16.13 \\
19.31\end{array}$ & $\begin{array}{l}6.57 \\
6.92\end{array}$ & $\begin{array}{r}10.90 \\
7.84\end{array}$ & $\begin{array}{l}6.07 \\
2.89\end{array}$ & $\begin{array}{l}-.518^{*} \\
-.621 \dagger \dagger\end{array}$ \\
\hline Nonretarded & $\begin{array}{l}\text { FI } \\
\text { FD }\end{array}$ & $\begin{array}{l}41 \\
16\end{array}$ & $\begin{array}{l}17.04 \\
20.06\end{array}$ & $\begin{array}{l}5.86 \\
4.41\end{array}$ & $\begin{array}{l}9.18 \\
5.81\end{array}$ & $\begin{array}{l}4.56 \\
2.35\end{array}$ & $\begin{array}{l}-.481 \dagger \\
-.576 * *\end{array}$ \\
\hline Total & $\begin{array}{l}\text { FI } \\
\text { FD }\end{array}$ & $\begin{array}{l}56 \\
57\end{array}$ & $\begin{array}{l}16.80 \\
19.52\end{array}$ & $\begin{array}{l}6.01 \\
6.29\end{array}$ & $\begin{array}{l}9.64 \\
7.27\end{array}$ & $\begin{array}{l}5.01 \\
2.88\end{array}$ & $\begin{array}{l}-.496 \dagger \dagger \\
-.595+\dagger\end{array}$ \\
\hline
\end{tabular}

${ }^{*} p=.04 . \quad{ }^{* *} p=.01 . \quad t p=.001 . \quad$ t† $p=.0001$.

latencies $[F(1,112)=5.61, p<.01$, and $F(1,112)=$ $14.33, \mathrm{p}<.0003$, respectively]. Table 3 presents the mean error and latency scores and the correlation coefficients for subjects categorized as field independent or field dependent. Field-independent youngsters made significantly fewer errors and had longer reaction times on the MFFT. The EMR-nonretarded results agreed with those originally reported; that is, no significant differences were observed between the two groups in MFFT performance.

Finally, intercorrelation coefficients were established between IQ and performance indexes on both dependent measures. IQ was not significantly related to MFFT errors $(r=.041, p=.65)$, latency $(r=-.034, p=.71)$, or the number of correct responses on the CEFT $(\mathrm{r}=.188, \mathrm{p}=.15)$. Accordingly, no significant correlations were observed when the subjects were categorized as retarded/nonretarded or male/female.

\section{DISCUSSION}

In comparison with nonretarded youngsters, EMR children did not respond more rapidly or with less accuracy on the MFFT. This observation parallels the findings of the Borys and Spitz (1978) investigation, despite their initial argument suggesting that, as a group, retarded individuals perform poorly on certain problem solving tasks due to rapid, careless responding. It is unlikely, therefore, that an impulsive disposition contributes to the observed decrement in the problem solving ability of retarded children. One could further interpret the results as suggesting that on visual search tasks, EMR children employ cognitive strategies similar to those of nonretarded students, although a distinction between perceptual and cognitive functions is not always clear.

Consistent with the findings of Nesbit and Chambers (1976), the retarded subjects were significantly more field dependent than their nonretarded counterparts. This may possibly be due to the inefficient or inappropriate use of mediators in a learning situation. Witkin and his collaborators (Witkin, Moore, Goodenough, \& Cox, 1977) have suggested that field-independent persons are more likely to generate mediating structural rules of their own design to facilitate learning than are field-dependent individuals, who are more likely to rely on characteristics of the learning task itself and, hence, experience greater difficulty in learning the material. However, if the hypothesis of comparative cognitive strategies between retarded and nonretarded children is plausible, additional explanation is required. It appears reasonable to speculate that retarded pupils with an MA equal to that of their nonretarded peers would also employ mediators to 
facilitate their learning. The EMRs, however, were possibly unable to effectively use mediators to enhance their performance due to a production deficiency (Flavell, Beach, \& Chinsky, 1966), whereby they failed to produce the necessary mediators at the appropriate time and thus responded in a global, undifferentiated fashion that resulted in an inefficient performance.

As anticipated, impulsive youngsters were significantly more field dependent. This may be related to the similarity of requirements for the MFFT and the CEFT. Both assessment instruments contain response ambiguity and necessitate scanning and analysis of a visual field. Ault, Crawford, and Jeffrey (1972) have demonstrated that the stimulus-scanning strategies of impulsive youngsters are less systematic and more global than those of reflective individuals. Also, reflective subjects more accurately evaluate the stimulus field and pay more attention to feature differences (Messer, 1976). This idea is congruent with Kilburg and Siegel's (1973) thesis that the differential performance of impulsive and reflective children is due to a quantitative difference in the thoroughness of the process of feature analysis, rather than to a qualitative or process difference.

The predicted relationship between performance on the MFFT and FD/I was partially supported. Error scores on the MFFT were significantly related in a negative fashion to the number of correct responses on the CEFT; that is, the more errors committed on the MFFT, the fewer responses were correct on the CEFT. Children who were unable to choose the correct response alternative on the MFFT were also inept at isolating embedded figures. This suggests that the critical factor in both cognitive styles is an error component that may possibly be related to the inability to perform detailed visual feature analysis. This inability is perhaps the most significant aspect of the cognitive-perceptual process underlying both tasks.

Intelligence was found to be unrelated to either $\mathrm{R} / \mathrm{I}$ or $\mathrm{FD} / \mathrm{I}$ even when subjects were separated by as much as 30-50 IQ points. This observation parallels the data from the Borys and Spitz (1978) investigation, in which significant correlations between IQ and errors and IQ and latency were also not in evidence. Messer (1976) has suggested, however, that MFFT-IQ correlations may be a function of age, with higher correlations existing for preschoolers. Yet the type of intelligence measure used to assess intellectual ability has also been demonstrated to influence the magnitude of the correlation coefficients (Messer, 1976). Instruments primarily verbal in nature generate smaller coefficients in contrast to the nonverbal, pictorial multiplechoice variety. Thus, the absence of a significant relationship between IQ and the dependent measures might have been due to the CA of the subjects, although larger, and possibly significant, coefficients would have been expected due to the type of intelligence scale employed. Therefore, one may wish to conservatively interpret this finding.

Individual differences in cognitive style may be related to classroom performance. Academic success probably requires both accurate field differentiation and organization and the ability to control or delay speed of response (Keogh \& Donlon, 1972). Thus, a learner who is unable to monitor his response output and tends to respond rapidly, without regard for accuracy, will not meet the school's demands either academically or behaviorally. It is reasonable to expect, therefore, that teachers be sensitive to individual differences in cognitive styles and attempt to match the child's cognitive disposition with the characteristics of the program or instructional setting in which he or she must function. Inclusion of cognitive style as a significant component in educational planning may maximize learning efficiency.

\section{REFERENCE NOTE}

1. Davis, J. Concept identification of the functioning of cognitive style complexity and training procedures (Tech. Rep. 32).
Madison: Wisconsin Research and Development Center for Cognitive Learning, 1967.

\section{REFERENCES}

Ault, R., Crawford, D., \& Jeffrey, W. Visual scanning strategies of reflective, impulsive, fast-accurate, and slow-inaccurate children on the Matching Familiar Figures Test. Child Development, 1972, 43, 1412-1417.

Barr, A., Goodnight, J., Sall, J., \& Helwig, J. Statistical analysis system. Raleigh, N.C: SAS Institute, 1979.

Borys, S., \& SPITz, H. Reflection-impulsivity in retarded adolescents and nonretarded children of equal MA. American Journal of Mental Deficiency, 1978, 82, 601-604.

Camprell, S. Cognitive styles in reflective, impulsive and hyperactive boys and their mothers. Perceptual and Motor Skills, $1973,36,747-752$.

Campbell, S., \& Douglas, V. Cognitive styles and responses to the threat of frustration. Canadian Journal of Behavioural Science, 1972, 4, 30-42.

Dunn, L. Peabody picture vocabulary test. Circle Pines, Minn: American Guidance Service, 1965.

Everitt, B. The analysis of contingency tables. London: Chapman-Hall, 1977.

Flavell, J., Beach, D., \& Chinsky, J. Spontaneous verbal rehearsal in a memory task as a function of age. Child Development, 1966, 37, 283-299.

KAGAN, J., \& KogAN, N. Individual variation in cognitive process. In P. Mussen (Ed.), Carmichael's manual of child psychology (Vol. 1). New York: Wiley, 1970.

Kagan, J., Rosman, B., Day, D., Albert, J., \& Philips, W. Information processing in the child: Significance of analytic and reflective attitudes. Psychological Monographs, 1964, 78(1, Whole No. 578).

KARP, S., \& Konstadt, N. Children's embedded figures test. Palo Alto, Calif: Consulting Psychologists Press, 1971.

KeOGH, B. Perceptual and cognitive styles: Implications for special education. In L. Mann \& D. Sabatino (Eds.), The first review of special education. Philadelphia: Journal of Special Education Press, 1973.

Keogh, B., \& Donlon, G. Field dependence, impulsivity, and learning disabilities. Journal of Learning Disabilities, 1972, 5, 331-336.

Kilburg, R., \& Siegel, A. Differential feature analysis in the recognition memory of reflective and impulsive children. Memory \& Cognition, 1973, 1, 413-419.

MASSARI, D. The relation of reflection-impulsivity to field dependence-independence and internal-external control in children. Journal of Genetic Psychology, 1975, 126, 61-67.

Messer, S. Reflection-impulsivity: A review. Psychological Bulletin, 1976, 83, 1026-1052.

Nesbit, W., \& Chambers, J. Performance of MA matched nonretarded and retarded children on measures of field-dependence. American Journal of Mental Deficiency, 1976, 80, 469-472.

Schleifer, M., \& Douglas, V. Moral judgements, behaviour, and cognitive style in young children. Canadian Journal of Behavioural Science, 1973, 5, 133-144.

Witkin, H., Dyk, R., Faterson, H., Goodenough, D., \& KARP, S. Psychological differentiation. New York: Wiley, 1962.

Witkin, H., Moore, C., Goodenough, D., \& Cox, P. Fielddependent and field-independent cognitive styles and their educational implications. Review of Educational Research, $1977,47,1-64$

\section{NOTE}

1. The Matching Familiar Figures Test is available from Jerome Kagan, William James Hall, Harvard University, 33 Kirkland Street, Cambridge, Massachusetts 02138.

(Received for publication October 1, 1981.) 